\title{
Teaching Students to Create Independent Equations based on Solving Problems by Constructing Equations
}

\author{
Berdiyev Bakhodir Ravshanovich ${ }^{1}$, Shodiyev Rizamat Davronovich ${ }^{2}$ \\ sharopovr@bk.ru \\ ${ }^{1}$ Senior teacher, Department of Primary Education, Karshi State University, Uzbekistan \\ ${ }^{2}$ Professor of Pedagogical Sciences, Karshi State University, Uzbekistan
}

\begin{abstract}
Nowadays, the science of mathematics is advancing rapidly. Scientists are working on new examples and issues awaiting a new solution. This article focuses on teaching students to do mathematical problems independently in elementary grades using equations. The result of the study suggest that Each teacher should stimulate students in the classroom, develop children's skills in mathematics, the ability to make equations and inequalities, and solve them independently. It allows them to solve problems independently by creating mathematics proficiency equations in upper grades.
\end{abstract}

Keywords: Equations, Ingenuity, Unknown Values, Arithmetic, Algebra

Received: November 4, 2020

Received in Revised: November 14, 2020

Accepted: November 23, 2020

\section{Introduction}

In primary school math classes, there are also textual problems with examples, and it is important to solve such problems by constructing equations. Because solving problems with the help of equations expands the thinking of primary school pupils, develops their thinking skills, encourages pupils to be resourceful.

Prior research has focused exclusively on students' use of multiple strategies and/or use of efficient strategies (Durkin et al, 2017; Heinze, 2009 ; Montague, 2008; Gartmann \& Freiberg, 1995).

The present study also included independent measures of strategy knowledge, including knowledge of multiple solution strategies and knowledge of strategy efficiency. With respect to the first, both prompts to discover multiple ways and direct instruction via a strategy demonstration helped students accept that there are multiple ways to solve equations and to be able to identify possible next steps. Knowledge of strategy efficiency was also improved by both instructional interventions: prompted multiple ways and strategy demonstration on multiple strategies led students to recognize more adaptive strategies (e.g., more efficient ones) and to implement efficient strategies when prompted (Star, 2008).

The present study underscores the importance of disentangling knowledge from use and multiple strategies from efficient strategies. First, research on metacognitive skills and utilization deficiencies both suggest that learners develop knowledge that they do not always use effectively (Miller \& Seier, 1994; Veenman, Kok, \& Blöte, 2005)

Our analysis reveals that responding to those challenges entailed formulating and addressing particular instructional goals, previously unfamiliar to the instructor. From a cognitive analytical perspective, we argue that the instructor's knowledge - or lack of knowledge influenced his ability to set and accomplish his instructional goals as he planned for, reflected on, and enacted instruction. By studying the teaching practices of a professional 
mathematician, we identify forms of knowledge apart from mathematical content knowledge that are essential to reform-oriented teaching, and we highlight how knowledge acquired through more traditional instructional practices may fail to support research-based forms of student-centered teaching (Wagner, Speer \& Rossa, 2007).

\section{Methods}

Solving simple problems using equations starts in 2 nd grade. We know that the thinking ability and consciousness of 4th graders are distinguished by the breadth of the scope of thinking according to the minds of 1st, 2nd, 3rd graders. Therefore, it is important to teach 4 th graders to solve complex problems by constructing equations. There are examples and problems in Grade 4 mathematics in which the values of an unknown number are given in the same example. In this case, the unknown letter $\mathrm{x}$ can also be given by the letters $\mathrm{a}, \mathrm{b}, \mathrm{d}, \mathrm{e}$.

For example: If $\mathrm{a}=20$,

find the sum of $a+30$ and the difference of $90-a$.

Solution: $\mathrm{a}+30=20+30=50$ and $90-\mathrm{a}=90-20=70$

We will look at some ways to work out problems that can be solved using equations from the 4th-grade math textbook.

Task 1: In the morning there was $17 \mathrm{tn} 280 \mathrm{~kg}$ flour in the store. In the afternoon $6 \mathrm{tn}$ $60 \mathrm{~kg}$ flour left. How many $\mathrm{kg}$ of flour was sold? Solution: We denote the flour sold here by $\mathrm{x}$ because it is not known how much flour was sold during the day.

$$
\begin{aligned}
& 17 \text { th } 280 \mathrm{~kg}-\mathrm{x}=6 \mathrm{tn} 60 \mathrm{~kg} \\
& \mathrm{x}=17 \mathrm{tn} 280 \mathrm{~kg}-6 \mathrm{tn} 60 \mathrm{~kg} \\
& \mathrm{x}=11 \mathrm{tn} 220 \mathrm{~kg}
\end{aligned}
$$

Answer: $11 \mathrm{tn} 220 \mathrm{~kg}$ of flour was sold from the store.

Task 2: The unknown number was multiplied 3 times, resulting in 1083 when 192 was added to the result. Find the unknown number.

$$
\begin{aligned}
& x \cdot 3+192=1083 \\
& 3 x=1083-192 \\
& \text { Solution: } 3 x=891, \\
& x=891: 3 \\
& x=297
\end{aligned}
$$

Answer: The unknown number is 297.

In Grade 4, pupils are taught to solve equations involving four arithmetic operations along with multi-digit numbers. In doing so, the effectiveness of the lesson is enhanced when students are taught to solve problems using a non-traditional method, i.e. an interactive method, rather than always in a traditional way. The reason is that didactic games and interactive methods are an important motivator for pupils to participate in the lesson more actively and attentively.

The role of didactic games in the formation of motives in primary education is invaluable. There can be no development without a game. Games are a spark that arouses pupils' passion and interest in knowledge. 
It does not require specific materials or conditions but requires knowledge and skills from the primary school teacher in the field of the game organization. Only the organization of the game based on a certain system and methodology plays an important role in developing pupils' ability to think independently.

Let's take a look at one such game for 4th graders: the "Who's Faster" game.

We will use the game "Who is faster" to solve the following problems. Accordingly, the class is divided into 2 groups, according to which the board is also divided into 2 parts. The issues are then conditionally announced by the teacher to the game participants. That is, group 1 solves problem 1, group 2 solves problem 2 . The group that completes the task quickly and correctly is the winner and to this group is given incentive cards.

Task 1: 3 bags of potatoes taken from one furrow, 4 bags of potatoes from the other furrow. The mass of all the potatoes is $315 \mathrm{~kg}$. How many $\mathrm{kg}$ of potatoes were taken from each furrow?

Solution: We denote the $\mathrm{kg}$ of potatoes from each furrow by $\mathrm{x}$.

$$
\begin{aligned}
& 3 x+4 x=315 \\
& 7 x=315 \\
& x=315: 7 \\
& x=45
\end{aligned}
$$

which means that each bag contains $45 \mathrm{~kg}$ of potatoes.

From this we find: $3 \mathrm{x}=3 \cdot 45=135$ and

$4 \mathrm{x}=4 * 45=180$.

Answer: $135 \mathrm{~kg}$ of potatoes were obtained from the first furrow and $180 \mathrm{~kg}$ from the second.

Task 2: 18 boxes of vegetables were brought to one store and 15 boxes of such vegetables to another. $24 \mathrm{~kg}$ many vegetables were brought to the second store than the first. How many $\mathrm{kg}$ of vegetables are delivered to each store?

Solution: We denote the $\mathrm{kg}$ of vegetables in each box by $\mathrm{x}$.

Need to find: $18 \mathrm{x}, 15 \mathrm{x}=$ ?

$$
\begin{aligned}
& 15 x+24=18 x \\
& 18 x-15 x=24 \\
& 3 x=24 \\
& x=24: 3
\end{aligned}
$$

We find $\mathrm{x}=8$, of which $18 \mathrm{x}=18 \cdot 8=144$,

$$
15 \mathrm{x}=15 \cdot 8=120
$$

Answer: $144 \mathrm{~kg}$ vegetables were delivered to the first store and $120 \mathrm{~kg}$ to the second.

Nowadays, the science of mathematics is developing rapidly. Our scientists are working on new examples and problems waiting for a new solution. Today we are going to look at the concept of an equation with you: first, we will define the equation. An equality involving an unknown number denoted by a letter is called an equation. 


$$
\begin{aligned}
& 3 x-90=270 \\
& 3 x=360 \\
& X=360: 3 \\
& X=120
\end{aligned}
$$

Here the root of equation is 120 . The root of an equation is the value of the unknown that converts equation to the correct equality. The equation may also not have roots. For example, the equation $2 x+5=2 x+3$ has no roots, because at any value of $x$ the left-hand side of this equation will be larger than the right-hand side. Solving an equation means finding all its roots or showing that they don't exist. The following basic properties of the equation are used in solving the equation.

It is possible to change any sign of the equation from one part of it to another by changing it to the opposite. Both parts of the equation can be multiplied or divided by the same number that is not equal to zero. The Language of Algebra Equations "to solve questions concerning the abstract relation of numbers or quantities, we must simply transfer the problem from our language to the language of algebra," wrote the great Newton in his textbook of algebra, Equal Arithmetic. Newton showed in examples how to perform the transition from the native language to the language of algebra.

Here is one of them:

\begin{tabular}{|l|c|}
\hline \multicolumn{1}{|c|}{ In the native language } & In the language of algebra \\
\hline The merchant had a certain amount of money & $\mathrm{x}$ \\
\hline The first year he spent $£ 100$ & $(\mathrm{x}-100)+\frac{\mathrm{x}-100}{3}=\frac{4 \mathrm{x}-400}{3}$ \\
\hline He added a third of it to the remaining sum & $\frac{4 \mathrm{x}-400}{3}-100=\frac{4 \mathrm{x}-700}{3}$ \\
\hline The following year he spent another $£ 100$ & $\frac{4 \mathrm{x}-700}{3}+\frac{4 \mathrm{x}-700}{9}=\frac{16 \mathrm{x}-2800}{9}$ \\
\hline $\begin{array}{l}\text { and increased the remaining sum by one-third of } \\
\text { it }\end{array}$ & $\frac{16 \mathrm{x}-2800}{9}-100=\frac{6 \mathrm{x}-3700}{9}$ \\
\hline $\begin{array}{l}\text { In his third year, he spent another } £ 100 \\
\text { He then added a third of it to the remainder }\end{array}$ & $\frac{16 \mathrm{x}-3700+\frac{16 \mathrm{x}-3700}{27}=\frac{64 \mathrm{x}-14800}{27}}{9}$ \\
\hline His capital was twice that of the original & $\frac{64 \mathrm{x}-14800}{27}=2 \mathrm{x}$ \\
\hline
\end{tabular}

It remains to solve the final equation to determine the initial capital of the merchant. Solving an equation is not difficult in most cases, it is more difficult to construct the equations based on the conditions of the problem. You have just seen that the art of constructing equations leads to a transition from "mother tongue to algebraic language". The language of algebra is sparse, so it is possible to easily translate phrases that do not have a lot of native languages. There are transitions in various difficulty, which the reader will be convinced of in a series of examples of the construction of first-level equations. There are several types of equations. For example, one-dimensional equations, linear equations, quadratic equations, higher-level equations, and so on. Primary school pupils mostly do examples and problems on an unknown equation.

Along with these equations, we also study the concept of inequalities. The inequalities include " $>$ ", "<", " $\geq$ ", " $\leq$ ", "=". e.g. The number a is greater than the number $b$. It is written in the form "a> b". There are also different types of inequality, e.g., quadratic inequality, linear 
inequality, parametric inequality, and so on. It means finding all the solutions to solve the inequality or showing that there are none.

\section{Conclusion}

In conclusion, the main purpose of introducing the concept of equations studied in primary school is to develop pupils' independent calculation skills, to form abstract concepts, and of course, to teach the rules of sequencing in the process of working equations. This means that every teacher must activate pupils in the classroom, develop children's mathematical skills, the ability to create equations and inequalities, and solve them independently. Completing the problems independently by constructing equations allows them to master mathematics in the upper grades.

\section{References}

Durkin, K., Star, J. R., \& Rittle-Johnson, B. (2017). Using comparison of multiple strategies in the mathematics classroom: Lessons learned and next steps. ZDM, 49(4), 585597.

Gartmann, S., \& Freiberg, M. (1995). Metacognition and mathematical problem solving: Helping students to ask the right questions. The Mathematics Educator, 6(1).

Heinze, A., Star, J. R., \& Verschaffel, L. (2009). Flexible and adaptive use of strategies and representations in mathematics education.

Miller, P. H., \& Seier, W. L. (1994). Strategy utilization deficiencies in children: when, where, and why. In H. W. Reese (Ed.), Advances in child development and behavior, Vol. 25 (pp. 107e156). New York: Academic.

Montague, M. (2008). Self-regulation strategies to improve mathematical problem solving for students with learning disabilities. Learning Disability Quarterly, 31(1), 37-44.

Star, J. R., \& Rittle-Johnson, B. (2008). Flexibility in problem solving: The case of equation solving. Learning and instruction, 18(6), 565-579.

Veenman, M. V., Kok, R., \& Blöte, A. W. (2005). The relation between intellectual and metacognitive skills in early adolescence. Instructional Science, 33(3), 193-211.

Wagner, J. F., Speer, N. M., \& Rossa, B. (2007). Beyond mathematical content knowledge: A mathematician's knowledge needed for teaching an inquiry-oriented differential equations course. The Journal of Mathematical Behavior, 26(3), 247-266. 